International Journal of Arts and Humanities Studies (IJAHS)

ISSN: $2754-4311$

DOI: 10.32996/ijahs

Journal Homepage: www.al-kindipublisher.com/index.php/ijahs

\title{
Self-Esteem, Self-Control and Deviant Behavior of HUMSS Senior High School Students
}

\author{
Hercel D. Rubite \\ Teacher II, Senior High School Coordinator, San Roque-Ezpeleta National High School, San Roque, Anini-y,Antique, Phillippines \\ $\square$ Corresponding Author: Hercel D. Rubite, E-mail: hercel.rubite@deped.gov.ph
}

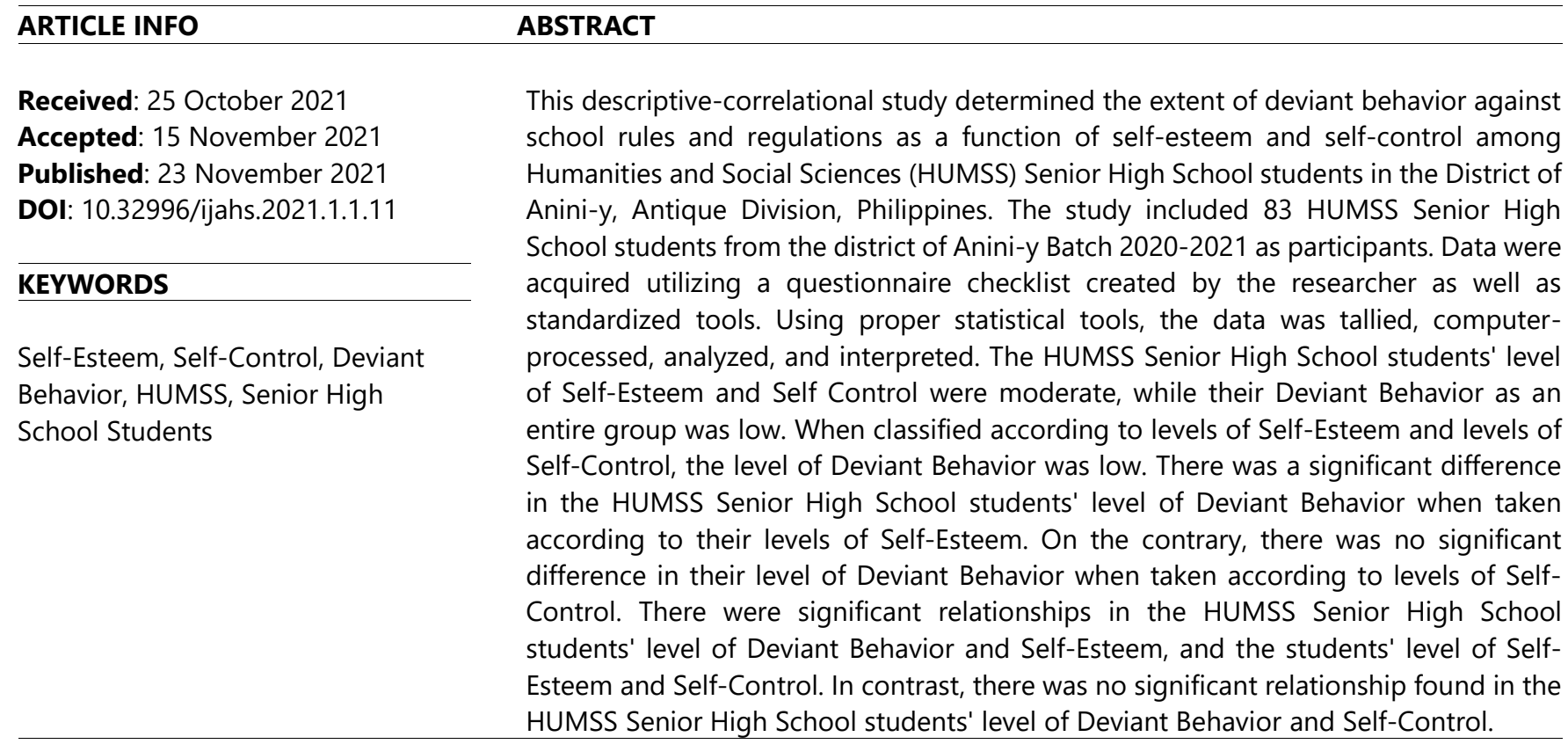

\section{Introduction}

Clinard and Meier (2011) said that deviance comes in all forms from minor transgressions that are barely noticed

to major behavior that has significant consequences. What unites all of the diverse behavior is that they all violate some norm or an expectation of behavior in certain situations. Because norms change, so too will the form that deviance takes change. They are bound to be new and emerging forms of deviance.

With the current prominence of remote $\&$ online learning due to the covid19 pandemic, virtual teaching strategies have become widespread \& indeed necessary. Pedroso (2021) pointed out that "webinars are a convenient and flexible tool for teaching and learning. Though, webinars have advantages and disadvantages, when used to the fullest, can promote a culture of reflection to further advance the cause of producing holistic students." Whereas if not handled effectively, this might also lead to difficulties and could eventually result in minor deviant acts among students in the "new normal" set-up of education.

At the workplace of the researcher, certain deviant behaviors among students have also been observed through the years. This includes dishonesty in doing outputs and cheating during exams, late submission of learning activity sheets, using gadgets for personal leisure during class hours, and habitual tardiness of students in attending classes. There were students caught submitting subject requirements having exactly the same, verbatim contents. This may be due to the temptation of easier access to internet information and ease in forwarding answers and outputs among students virtually especially in remote learning as well as online/ modular classes.

While most students conform to the norms and standards of the school, there are always a few who would choose to violate the established rules and regulations. If these minor offenses will be neglected by the school and left unchecked, they will surely cause

Copyright: (c) 2021 the Author(s). This article is an open access article distributed under the terms and conditions of the Creative Commons Attribution (CC-BY) 4.0 license (https://creativecommons.org/licenses/by/4.0/). Published by Al-Kindi Centre for Research and Development, London, United Kingdom. 
more serious violations in the future. Moreover, another interesting phenomenon observed is that those who violate school rules are also observed to be confident in doing so they dare to do it. Sometimes having a fight with a classmate, a student is not bothered by breaking the rules just to secure vengeance. There are also those who are confident to bring \& use gadgets prohibited during classes. What puzzles the researcher is that "Do deviant behaviors always coupled with self-control and self-esteem?", "Does having high levels of self-esteem would result in a higher frequency of deviant acts?" or "Does having self-control also mean one has control towards his/ her deviant act tendencies?". Deviance, self-control, and self-esteem are indeed a reality in today's classrooms and learning environments. It comes in many forms and it results in different consequences. Apart from its obvious observation by education implementers, it would be more helpful if it is coupled with empirical research and investigation. With all its complexities and dynamism, the researcher finds these topics a timely issue worthy to be pondered.

\section{Methodology}

\subsection{The Participants}

The participants of this study were the 83 students of San Roque-Ezpeleta National High School as well as students from St. Therese's High School, Inc., which were the only two schools offering the HUMSS strand in the District of Anini-y, Division of Antique, the Philippines utilizing the stratified random sampling as the sampling method. The Australian Bureau of Statistics (2020) defines stratified sampling as a technique that uses auxiliary information available for every unit on the frame to increase the efficiency of a sample design. Stratified sampling involves the division (stratification) of the population frame into non-overlapping, homogeneous (similar) groups called strata, which can be treated as totally separate populations. A sample is then selected independently from each of these groups, and can therefore be selected in different ways for different strata, e.g. some strata may be sampled using 'simple random sampling' while others may be 'completely enumerated'. These terms are explained below. Stratification variables may be geographical (e.g. State, capital city/balance of State) or non-geographical (e.g. number of employees, industry, turnover).

\subsection{The Research Instruments}

The researcher provided a questionnaire checklist composed of two parts. Part One was for the information about the participants such as their grade level. Part Two, composed of the test questionnaire checklist proper. Questionnaire-checklist one was a 21 item level of deviant behavior tool based on school rules and regulations. Questionnaire-checklist two was the Level of Self-Esteem Tool based on the Rosenberg Self-Esteem Scale. Questionnaire-checklist three was based on the Self-Control Scale Adapted from Tangney, Baumeister, \& Boone (2004). A letter of permission was sent via e-mail to Dr. June P. Tangney for the use of her developed self-control tool. The permission was granted with a positive response from the author. The instruments had been conducted to HUMSS students from Diclum National High School, a school located in a different district, for pilot testing. The results showed a Cronbach's Alpha of 0.739 for Self-Esteem Tool, 0.812 for Self-Control Tool, and 0.905 for Deviant Behavior Against School Rules \& Regulations Tool, which are all higher than 0.70 , thus, an indicator of reliable statements in the research instruments.

\subsection{Data Gathering Procedure}

In conducting the study, the researcher submitted a tentative draft of the researcher-made questionnaire checklist on deviant behavior as well as the standardized tools on self-esteem \& self-control to the validators who are experts in the field of research and social sciences. Communication via e-mail reflecting consent \& permission from the author of the self-control tool was beforehand secured by the researcher. After validation and prior to the pilot-testing of the questionnaire, a letter of permission to conduct the study was foremost secured from the Office of the Schools Division Superintendent, Division of Antique. Upon approval, another permit is sought from the Office of School Principals with the approved request attached. Once permitted, the researcher met virtually with the advisers as well as the students of the said school for a short introduction of the study and convinced them to participate. The final draft of the questionnaire was then prepared for administration. When everything is set, the researcher together with the participants mutually calendar the schedule of administration of research instruments. Originally, to ensure the internal validity of this study, the participants were gathered in one room; ask not to communicate while filling out the questionnaire, and presents statements which the participants cannot predict. The instrument is retrieved as soon as the respondents accomplished it. However, due to the current pandemic that we experienced, the researcher chose to administer the questionnaire checklist as well as communicate and follow up with the advisers and respondents using online platforms for safety purposes. The collected data were immediately tallied, computer-processed, and interpreted.

\subsection{Statistical Data Analysis Procedure}

The gathered data are immediately run through Statistical Package for Social Sciences (SPSS) software using the following statistical treatments: Descriptive Statistics: Frequency Counts, Mean, \& Standard Deviation, Inferential Statistics: One-Way Analysis of Variance or ANOVA \& Pearson product-moment Correlation Coefficient (Pearson's r).

\section{Results}

Table 1. Students' Self-Esteem and Self Control 


\begin{tabular}{lllll}
\hline & N & SD & Mean & Description \\
\hline Self-Esteem & 83 & .39 & 1.78 & Moderate \\
Self-Control & 83 & .47 & 3.07 & Moderate \\
\hline
\end{tabular}

Table 1 shows the students' self-esteem and self-control were both "Moderate" $(M=1.78, S D=0.39)$ and (M=3.07, SD=0.47), respectively.

Table 2. Level of Deviant Behavior When Taken According to Levels of Self-Esteem

\begin{tabular}{cllll}
\hline Self-Esteem & N & SD & Mean & Description \\
\hline Low & 2 & .20 & 1.91 & Low \\
Moderate & 61 & .51 & 1.73 & Low \\
High & 20 & .22 & 1.45 & Low \\
TOTAL & 83 & .47 & 1.67 & Low
\end{tabular}

Table 2 shows the level of Deviant Behavior of students when taken as an entire group and classified according to levels of selfesteem was "Low" ( $M=1.67, S D=0.47)$. When taken according to levels of self-esteem, the extent of deviant behavior for all selfesteem classification groups was "Low" ( $M=1.91, S D=0.20, M=1.73, S D=0.51, M=1.45, S D=0.22$, respectively).

Table 3. Level of Deviant Behavior when taken According to Levels of Self-Control

\begin{tabular}{cllll}
\hline Self-Control & N & SD & Mean & Description \\
\hline Low & 8 & .40 & 1.63 & Low \\
Moderate & 70 & .48 & 1.70 & Low \\
High & 5 & .22 & 1.28 & Low \\
TOTAL & 83 & .47 & 1.67 & Low \\
\hline
\end{tabular}

Table 3 shows that the student's level of deviant behavior was "Low" ( $M=1.67, S D=0.47)$. When taken according to levels of selfcontrol, the extent of deviant behavior for all self-control classification groups was "Low" $(M=1.63, S D=0.40, M=1.70, S D=0.48$, $M=1.28, S D=0.22$, respectively).

Table 4. ANOVA Result for the Significant Difference in the Level of Deviant Behavior when taken According to Self-Esteem

\begin{tabular}{|c|c|c|c|c|c|}
\hline & $\mathrm{N}$ & Mean & Df & $\mathrm{F}$ & Sig. (2-tailed) \\
\hline \multicolumn{6}{|l|}{ Groups } \\
\hline Low & 2 & 1.91 & & & \\
\hline Moderate & 61 & 1.73 & 2 & 3.226 & $0.045^{*}$ \\
\hline High & 20 & 1.45 & & & \\
\hline
\end{tabular}

${ }^{*} p<0.05$ significant

Table 4 shows that there was a significant difference in the students' level of deviant behavior among the categories of self-esteem $F(2,80)=3.226, p=0.045$.

Table 5. Post-hoc, Tukey HSD Test Multiple Comparison Result in Level of Deviant Behavior Among Various Levels of SelfEsteem

\begin{tabular}{clll}
\hline (I) Level of Self-Esteem & $(J)$ Level of Self-Esteem & Mean Difference (I-J) & P \\
\hline Low & Moderate & .17885 & .849 \\
Low & High & .46400 & .362 \\
Moderate & High & .28515 & $.046^{*}$ \\
\hline
\end{tabular}

${ }^{*} p<0.05$ significant 
To determine which of the levels of self-esteem contributed to the significant difference among the attitude of the students a post-hoc, Tukey HSD test was conducted to determine the multiple comparisons among the self-esteem levels. Results in table 5 reveal that there was a significant difference between moderate self-esteem level and high self-esteem level of students' deviant behavior as revealed in the significant value of .046 . This means that there was a significant difference in the deviant behavior of HUMSS senior high school students, showing that their level varies and this contributed to the difference.

Table 6. ANOVA Result for the Significant Difference in the Level of Deviant Behavior when taken According to Self-Control

\begin{tabular}{cllllll}
\hline & & $N$ & Mean & Df & F & Sig. (2-tailed) \\
\hline Groups & & & & & & \\
& Low & 8 & 1.63 & 2 & 1.902 & 0.156 \\
& Moderate & 70 & 1.70 & 1.28 & & \\
& High & 5 & & &
\end{tabular}

${ }^{*} p<0.05$ significant

Table 6 shows that there were no significant différences in the students' level of deviant behavior among the categories of selfcontrol $F(2,80)=1.902, p=0.156$.

Table 7. Pearson Product-Moment Correlation Coefficient to Show Relationship between Deviant Behavior and Self-Esteem

Pairs R Sig. (2-tailed)

Deviant Behavior

$-.312 .004^{*}$

Self-Esteem

Note: ${ }^{*} p<0.05$ significant

Table 7 shows that there was a significant relationship between the students' level of deviant behavior and self-esteem $(r=-0.312$, $p=.004)$.

Table 8. Pearson Product-Moment Correlation Coefficient to Show Relationship between Deviant Behavior and Self-Control Pairs $\mathrm{R}$ Sig. (2-tailed)

Deviant Behavior

Self-Control

Note: * $p<0.05$ significant

Table 8 shows that there was no significant relationship between the students' level of deviant behavior and self-control $(r=-0.040$, $p=.721)$.

Table 9. Pearson Product-Moment Correlation Coefficient to Show Relationship between Self-Esteem and Self-Control

Pairs $\mathrm{R} \quad$ Sig. (2-tailed)

Self-Esteem

$.000 *$

Self-Control

Note: * $\mathrm{p}<0.05$ significant

Table 9 shows that there was a significant relationship between the students' level of self-esteem and self-control ( $r=-0.376$, $p=.000)$.

\section{Discussion}


Students' moderate self-esteem may be influenced by their positive self-opinion, particularly in terms of how they feel about their strengths and limitations. This finding backs up Almogela et al study's in Baguio City. et al. (2013) discovered that public and private high school students have "average" levels of self-esteem. On the other hand, their moderate level of self-control suggests that they have exactly the correct amount of self-control when it comes to controlling their impulses, actions, and behavior. However, their low level of deviant behavior means that regardless of their self-esteem classification, they exhibit the same level of deviant behavior. The result on self-esteem about deviant behavior revealed similar results to the study Shoemaker (1992), who found a low level of self-reported delinquency in research done in the Philippines. Furthermore, when measured in terms of selfesteem, this result on student deviant conduct contradicts Tzing \& Yi's (2012) findings, which suggest that high self-esteem is not a protective factor of delinquency, contrary to popular belief.

HUMMS Senior High School students' low level of deviant behavior suggests that, despite their self-control levels, they engage in similar levels of deviant activity against school norms and regulations. The degree to which students can regulate and manage themselves does not always predict the type of deviant behavior they engage in in violation of school rules and regulations. This finding contradicts research conducted by Barrera et al. al. (2015) who found that self-control and differential association have direct effects on delinquency among Filipino students in Dumaguete City.

The mean score obtained by the students from the "low" self-esteem category, indicates that they are more likely to exhibit a little higher levels of deviant behavior than the students of "moderate" and "high" levels of self-esteem. It implies the notion that those students having low self-esteem are more likely to commit deviant behavior against school rules and regulations. They are the ones who usually commit minor delinquencies and violations of classroom rules \& procedures. These further showed that not all population means are equal, thus, rejecting the null hypothesis. This result affirms the self-esteem model of deviance, wherein juveniles may become involved in delinquency as a response to negative self-attitudes. In particular, self-derogation theory predicts that low self-esteem motivates youths to try out delinquent activities that are aimed at restoring self-esteem (Wells, 1989). This further supports the study of Rosenberg et. al. (1989) who found that self-esteem fosters delinquency and that delinquency may enhance self-esteem.

Although the mean scores of students with "moderate" levels of self-control have somewhat higher levels of deviant behavior considering little differences in percentage, nevertheless the findings when analyzed would mean that both students with low, moderate, and high levels of self-control have somewhat the same degree of deviant behavior against school rules $\&$ regulations. This implies that the groupings in levels of self-control as being low, moderate, and high had almost the same response on their levels of deviant behavior.

As the self-esteem of students gets higher, their level of deviant behavior against school rules \& regulations gets lower as seen by the negative correlation value revealed by this study. This result confirms the study of Trzesniewski et al. (2002) as cited in Gunes (2008), which is also praised by Baumeister et al. (2003) as being the "best available evidence for a positive link between low selfesteem and subsequent delinquent behavior". It found significant correlations between self-reported delinquency and three different measures of self-esteem. On the other hand, this result contradicts the findings of Lactao \& De Guzman (2011) who found no relationship between self-esteem and behavior problems as well as the studies of Zieman and Benson (1983) and Jang and Thornberry (1998) as cited in Gunes (2008) who both failed to find any relation between self-esteem and delinquency.

As there was no significant relationship between the students' level of deviant behavior and self-control, it means that even if the level of self-control among students goes up or down, it does not affect or in any way related to their level of deviant behavior against school rules and regulations. Moreover, it implies the acceptance of the null hypothesis. The result of this study contradicts the study conducted by Vazsonyi et. al. (2017) who found substantial empirical support for the main argument of self-control theory and on the transdisciplinary link between self-control and measures of crime and deviance.

As there was a significant relationship between the students' level of self-esteem and self-control. This means that as their level of self-esteem gets higher, the level of their self-control also gets higher, like in the study conducted by Tangney et. al. (2004). It was found a significant positive correlation between self-control and the Rosenberg self-esteem scale. The results further imply that people with high self-control accept themselves as valuable, worthy individuals and are relatively well able to sustain this favorable view of self across time and circumstances.

\section{Conclusion}

The HUMSS Senior High School students of the District of Anini-y, Division of Antique are just like most of their peers who have some positive self-assessment about their abilities and limitations. The way they see themselves is to a certain extent valuable and important. They also seem to have a good evaluation of their self-worth as a person. In terms of self-control, they can also manage their behavior in the same way that an average senior high school student behaves in school. This shows that they have some 
good beliefs in their capabilities and skills which resulted in good behavior. Their moderate level of self-control enables them to regulate their responses as they associate or relate with other students to avoid undesirable behavior.

It was found out that students with lower levels of self-esteem are the ones that are more likely to commit deviant behaviors. This validates the Self-derogation theory that those with low self-esteem may try out delinquent activities like breaking school rules and regulations to get attention and somehow boost their self-esteem. This further validates the study of Rosenberg that selfesteem fosters delinquency to enhance self-esteem. On the other hand, self-control which is the ability to regulate behavior does not influence the deviant activities of the respondents.

The positive relationship between self-esteem and self-control tends to prove the fact that people with low self-esteem cannot have self-control while those who have high self-esteem tend to have a good evaluation of their self-worth and eventually develop mastery of self which manifests in ones' behavior as they relate with other people.

Funding: "This research received no external funding"

Acknowledgments: To all the unsung heroes and heroines who made this paper possible, the researcher extends his heartfelt thanks!

Conflicts of Interest: "The authors declare no conflict of interest."

\section{References}

[1] Australian Bureau of Statistics. (2020). Overview of Survey Methods. Retrieved from https://www.abs.gov.au/ausstats/abs@.nsf/Lookup/by\%20Subject/6102.0.55.01 Feb\%202018 Main\%20Features Overview\%20of\%20Surve y\%20Methods 16\#: :text=Stratified\%20sampling\%20involves\%20the\%20division,treated\%20as\%20totally\%20separate\%20populations.

[2] Barrera, D J. (2015). The Interplay of Self-Control and Peer Influence in Filipino Delinquency. Prism. 20. 69-84.

[3] Clinard, M. B., \& Meier, R. F. (2011). Sociology of deviant behavior (14th ed.). Belmont, CA: Wadsworth.

[4] Gunes, I. D. (2008). Deviant Behavior Among Young Adults: Turkish Case With An Emphasis On Family Rituals, Self-Esteem And Religiosity. The University of North Texas. Retrieved from https://digital.library.unt.edu/ark:/67531/metadc6102/

[5] JLactao, L. S. De Guzman (2011). Academic Performance, Self-Esteem and Behavior Problems of Male Adolescents with Migrant-Working Fathers, ICERI2011 Proceedings, 4636-4645.

[6] Pedroso, J. E. P. (2021). Students' Views from Webinars: A Qualitative Study. International Journal of Arts and Humanities Studies (IJAHS), 1(1), 36-4. https://doi.org/10.32996/ijahs.2021.1.1.6 Retrieved from https://al-kindipublisher.com/index.php/ijahs/article/view/2276

[7] Rosenberg, M. (1965). Society and the adolescent self-image. Princeton, NJ: Princeton University Press. Retrieved from https://fetzer.org/sites/default/files/images/stories/pdf/selfmeasures/Self_Measur es_for_Self-Esteem_ROSENBERG_SELF-ESTEEM.pdf

[8] Rosenberg, M., Schooler, C., \& Schoenbach, C. (1989). Self-esteem and adolescent problems: Modeling reciprocal effects. American sociological review, 1004-1018. Retrieved from https://scholar.google.com/scholar_lookup?title=Selfesteem\%20and\%20adolescent\%20problem\%20behaviors\%3A\%20Modeling\%20reciprocal\%20effects\&journal=Am.\%20Sociol.\%20Rev.\&vol ume $=54 \&$ pages $=1004-1018 \&$ publication_year $=1989 \&$ \&author $=$ Rosenberg\%2CM.\&author $=$ Schooler\%2CC.\&author=Schoenbach\%2CC.\#d=gs_cit\&u=\%2Fscholar\%3Fq\%3Dinfo\%3AmgjLz9WD07MJ\%3Ascholar.google.com\%2F\%26ou tput\%3Dcite\%26scirp\%3D0\%26hl\%3Den

[9] Shoemaker, D. (1992). Delinquency in the Philippines: A Description. Philippine Sociological Review, 40(1/4), 83-103. Retrieved from http://www.jstor.org/stable/23898510

[10] Tangney, J. P., Baumeister, R. F., \& Boone, A. L. (2004). High Self-Control Predicts Good Adjustment, Less Pathology, Better Grades, and Interpersonal Success. Journal of Personality, 72(2), 271-324.

[11] Tzeng, S \& Yi, C. (2012). The Effects of Self-Esteem on Adolescent Delinquency over Time: Is the Relationship Linear?. DOI: 10.1007/978-94007-4081-5_12

[12] Vazsonyi, A. T., Mikuška, J and Kelley, E. L. (2017). It's time: A meta-analysis on the self-control-deviance link. Journal of Criminal Justice, Volume 48, 2017, Pages 48-63, ISSN 0047-2352, https://doi.org/10.1016/j.jcrimjus.2016.10.001.

[13] Wells, L. E. (1989). Self-Enhancement Through Delinquency: A Conditional Test of Self-Derogation Theory. Journal of Research in Crime and Delinquency, 26(3), 226-252. https://doi.org/10.1177/0022427889026003003 